\title{
QbD Approach for the Development and Validation of RP-UHPLC Method for Quantitation of Vildagliptin
}

\author{
Sharifa Sultana, Uttom Kumar, Md. Shahadat Hossain, Dilshad Noor Lira \\ and Abu Shara Shamsur Rouf
}

\author{
Department of Pharmaceutical Technology, Faculty of Pharmacy, University of Dhaka, Dhaka-1000, \\ Bangladesh
}

(Received: April 20, 2017; Accepted: June 09, 2017; Published (web): June 21, 2017)

\begin{abstract}
The present work describes a quality by design (QbD)-based rapid, simple, precise and robust RPUHPLC method for the routine analysis of vildagliptin in bulk drug and in pharmaceutical dosage forms. Chromatographic separation was achieved by a X-bridge $\mathrm{C}_{18}$ column with isocratic elution of mobile phase containing mixture of phosphate buffer $(\mathrm{pH} 6.8)$ and acetonitrile in the ratio of $67: 33(\mathrm{v} / \mathrm{v})$. The flow rate was 1.0 $\mathrm{ml} / \mathrm{min}$ and the detection was done at $239 \mathrm{~nm}$ with photo-diode array plus (PDA+) detector. The optimization of chromatographic method was carried out by QbD approach using design of experiments (DoE). Two factors utilized for the experimental design of the method were (i) independent variables which comprise percentages of acetonitrile in mobile phase and flow rate and (ii) co-variates which include the retention time, tailing factor and theoretical plates. This design was statistically analyzed by ANOVA, normal plot of residual, box-cox plot for power transform, perturbation, counter plot and 3D response surfaces plots. This was further validated as per the requirements of ICHQ2B guidelines for linearity, LOD, LOQ, accuracy, precision, specificity and robustness. The results showed that proposed method is simple, sensitive and highly robust for routine analysis of vildagliptin.
\end{abstract}

Key words: Vildagliptin, UHPLC, quality by design (QbD), development and validation, quantitation

\section{INTRODUCTION}

Vildagliptin [(S)-1-[N-(3-hydroxy-1-adamantyl) gly-cyl] pyrrolidine-2-carbonitrile] (Figure 1) is an oral antidiabetic drug belonging to the class of dipeptidyl peptidase-4 inhibitor(DPP-4) and is used in the treatment of type 2 diabetes as second line antihyperglycemic therapy. ${ }^{1-3}$ It is an oral incretin enhancer which acts to increase the levels of the incretin hormone glucagon-like peptide-1 (GLP-1) by inhibiting the dipeptidyl peptidase-4 responsible for the quick deactivation of GLP-1. As a result, glucosedependent functioning of pancreatic islet $\beta$ and $\alpha$ cells is improved. ${ }^{4}$ Though, the drug is not included in official pharmacopeia, it is available in tablet form and given alone or in combination therapy with metformin, sulfonylurea or thiazolidinedione. Galvus ${ }^{\circledR}$ is the innovator product of vildagliptin manufactured by Novartis. ${ }^{5,6}$

Correspondence to: Abu Shara Shamsur Rouf Email: rouf321@yahoo.com

Dhaka Univ. J. Pharm. Sci. 16(1): 107-117, 2017 (June)

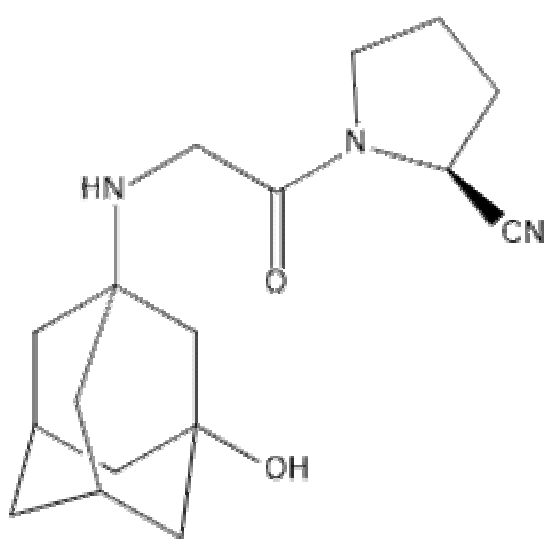

Figure 1. Structure of vildagliptin.

Different methods have been established for the determination of vildagliptin in various matrices like rat plasma ${ }^{7}, \operatorname{dog}$ plasma $^{8}$ and in human plasma by using LC-ESI-MS/MS and HPLC ${ }^{9,10}$ For estimation of vildagliptin alone and in combination few analytical methods i.e. HPLC, UV spectrophotometric methods have been reported. ${ }^{11-15}$ Among these analytical methods, though LC-MS 
method is most precise and accurate to analyze vildagliptin, it is not suitable for routine analysis in laboratory or pharmaceutical industries. However, UV spectro-photometry is the easiest method among these techniques but it has lack of accuracy, precision and needs relatively higher amount of analytes to be detected. Based on simplicity and sensitivity, HPLC is the best option to analyze vildagliptin as well as impurities determination. The currently available HPLC methods used either complex mobile phase system i.e. consisting more than two solvents or they have relatively higher retention time, low sensitivity etc. So, an attempt has been taken to develop a new RP-UHPLC method through QbD approach for the estimation of vildagliptin in bulk and tablet form with the aim to overcome these limitations. The concept of quality by design (QbD) has recently gained importance in the area of analytical method development by application of design of experiments approach (DoE). QbD involves understanding of the critical factors and their interaction effects by a desired set of experiments.

\section{MATERIALS AND METHODS}

Experimental materials and reagents. Vildagliptin powder (purity $>99.92 \%$; Dr. Reddy's Laboratories, India) was collected as a generous gift from Drug International Limited, Bangladesh. HPLC grade acetonitrile (RCI Labscan, Thailand), analytical grade potassium dihydrogen phosphate (Daejung Chemicals \& Metal Co. Ltd., Korea) and nano pure water (Evoqua Water Technologies) were used. All other reagents used were of analytical grade. Galvus ${ }^{\circledR}$ tablets labeled to contain $50 \mathrm{mg}$ of vildagliptin were collected from Novartis (Bangladesh) Limited.

Chromatographic conditions. The RP-UHPLC system consisted of Perkin Elmer Flexar series (autosampler, FX-15 binary pump, vacuum degasser, column oven and PDA plus detector) connected to a computer loaded with Chromera Manager Software was used for analysis. The chromatographic separation was achieved using X-bridge C18 (4.6 × $150 \mathrm{~mm}, 5 \mu \mathrm{m})$ column with isocratic elution of mobile phase consisting of mixture of phosphate buffer at $\mathrm{pH} 6.8$ and acetonitrile $(67: 33)$ at a flow rate of $1 \mathrm{ml} / \mathrm{min}$. The injection volume was $20 \mu \mathrm{l}$ and the detection was done at $239 \mathrm{~nm}$. All determinations were performed at $25^{\circ} \mathrm{C}$.

Stock and standard solutions. Stock solution of vildagliptin $(1 \mathrm{mg} / \mathrm{ml})$ was prepared in mobile phase. A working standard solution of $50 \mu \mathrm{g} / \mathrm{ml}$ was prepared from the stock solution by suitable dilution with a mobile phase. Standard solutions over the concentration range of $10-50 \mu \mathrm{g} / \mathrm{ml}$ were prepared from the working standard using the mobile phase.

Sample preparation. Galvus ${ }^{\circledR}$ tablets were crushed to finely grinded powder. A stock sample solution of $1 \mathrm{mg} / \mathrm{ml}$ was prepared in mobile phase by transferring a weighed amount of the powder equivalent to $100 \mathrm{mg}$ vildagliptin in a $100 \mathrm{ml}$ volumetric flask containing $50 \mathrm{ml}$ mobile phase. The solution was sonicated (Human Lab Instrument Co. Ltd., Korea) for $10 \mathrm{~min}$ and the volume was adjusted to the mark with mobile phase. The solution was then filtered (Whatman filter paper, Grade 1, $110 \mathrm{~mm}$ diameter) and stored in suitable container for further use. For assay of tablet, a sample solution of 50 $\mu \mathrm{g} / \mathrm{ml}$ was prepared from the stock solution by dilution with the mobile phase and filtered through $0.22 \mu \mathrm{m}$ disc filter (Filter-Bio).

Method development and experimental design. A novel RP-UHPLC method was developed using a mobile phase containing mixture of phosphate buffer at $\mathrm{pH} 6.8$ and acetonitrile (67:33) for achieving chromatographic separation. The experimental design and statistical analysis of data were performed by Design - Expert ${ }^{\circledR}$ software (version 10.0.3.1) using the Box-Behnken Design (BBD) since it requires fewer runs than a central composite design in cases of three or four variables to assess the robustness of the method. ${ }^{16}$ The independent variables selected were the acetonitrile concentration in mobile phase $(\mathrm{A}, \% \mathrm{v} / \mathrm{v})$ and flow rate $(\mathrm{B}, \mathrm{ml} / \mathrm{min})$. Retention time (RT) (R1, min), tailing factor (R2) and theoretical plate count (TP) $(\mathrm{R} 3, \mathrm{~N})$ were considered as covariates or independent variables. A 2-factor, 3-level BBD constructed 9 
experimental runs. Dependent and independent variables along with different levels are presented in table 1. The significance of the design was determined by the evaluation of statistical parameters i.e. ANOVA method and Good fit evaluation. The optimization of the method parameters was done on the basis of response surface method.

\section{Method validation}

The developed method for the quantitation of vildagliptin was validated as per ICH guidelines. ${ }^{17}$

System suitability test. System suitability was established by injecting $20 \mu \mathrm{l}$ each for six replicate injections of standard solution $(50 \mu \mathrm{g} / \mathrm{ml})$. The relative standard deviation (\% RSD) and mean tailing factor of responses were calculated.

Linearity. Appropriate dilutions of standard stock solution of vildagliptin $(10,20,30,40$ and 50 $\mu \mathrm{g} / \mathrm{ml}$ ) were assayed following the developed method. The limit of detection (LOD) and limit of quantitation (LOQ) were determined at the signal to noise ratio of $3: 1$ and 10:1, respectively.

Precision. Precision of the developed method was assessed by repeatability or intra-assay precision and intermediate precision analyses. Repeatability was determined from six replicate injections of $20 \mu \mathrm{l}$ each of nominal standard solution $(50 \mu \mathrm{g} / \mathrm{ml})$. The nominal standard solution was analyzed for a period of six days with six replicate injections of $20 \mu \mathrm{l}$ each on daily basis. The results of both the studies were compared (intermediate precision) and expressed as $\%$ RSD of the measurements.

Accuracy. To check for accuracy of the developed method as well as studying the interference of formulation additives on analysis the recovery experiments were carried out by spiking the sample solution with standard drug substance at $80 \%$, $90 \%, 100 \%, 110 \%$ and $120 \%$. All determinations were carried out in triplicate.

Specificity. Specificity was determined by injecting separately blank, standard and sample solution of vildagliptin in triplicate. The results were confirmed by the peak purity analysis.

\section{RESULTS AND DISCUSSION}

A factorial design using BBD was applied for observing the effect of two independent variables, the acetonitrile concentration in mobile phase (A), flow rate $(B)$, on three responses- retention time (R1), tailing factor (R2) and theoretical plate (R3) as parameters for optimization of proposed method. The chromatographic conditions and ranges fixed for selected variables are given in table 1 .

Table 1. Selection of independent variables and their levels.

\begin{tabular}{|c|c|c|c|c|c|c|c|c|c|}
\hline \multirow[t]{2}{*}{ Variables } & \multirow[t]{2}{*}{ Name } & \multirow[t]{2}{*}{ Unit } & \multirow[t]{2}{*}{ Type } & \multicolumn{3}{|c|}{ Coded values } & \multicolumn{3}{|c|}{ Actual values } \\
\hline & & & & Low & Mid & High & Low & Mid & High \\
\hline A & $\mathrm{ACN}$ & $\%$ & Numeric & -1 & 0 & 1 & 25 & 30 & 35 \\
\hline B & Flow Rate & $\mathrm{ml} / \mathrm{min}$ & Numeric & -1 & 0 & 1 & 0.8 & 0.9 & 1.0 \\
\hline
\end{tabular}

Table2. Box-Behnken experimental design using variables and their responses.

\begin{tabular}{ccccccc}
\hline Standard & Run & A: \% of ACN & B:Flow rate $(\mathrm{ml} / \mathrm{min})$ & $\begin{array}{c}\text { Retention time } \\
(\mathrm{min})\end{array}$ & Tailing factor & $\begin{array}{c}\text { Theoretical plate } \\
\text { count }\end{array}$ \\
\hline 8 & 1 & 0 & -1 & 2.95 & 1.372 & 5112 \\
2 & 2 & 0 & -1 & 3.50 & 1.386 & 5214 \\
5 & 3 & 0 & 0 & 2.91 & 1.372 & 5112 \\
6 & 4 & 1 & 0 & 2.96 & 1.453 & 5464 \\
7 & 5 & -1 & 1 & 3.55 & 1.291 & 5079 \\
4 & 6 & -1 & 1 & 4.03 & 1.303 & 5076 \\
9 & 7 & 1 & -1 & 2.54 & 1.431 & 5272 \\
3 & 8 & 1 & -1 & 3.25 & 1.445 & 5646 \\
1 & 9 & -1 & & 4.57 & 1.311 & 5257 \\
\hline
\end{tabular}


Table 3. ANOVA results for response R1 (RT).

\begin{tabular}{lcccccc}
\hline Source & Sum of squares & Df & Mean square & F value & p-value & Significance \\
\hline Model & 2.79 & 2 & 1.40 & 23.39 & 0.0015 & Significant \\
A- \% of ACN & 1.92 & 1 & 1.92 & 32.09 & 0.0013 & 0.0086 \\
B-Flow Rate & 0.88 & 1 & 0.88 & 14.70 & & \\
Residual & 0.36 & 6 & 0.060 & & & \\
Cor Total & 3.15 & 8 & & & \\
\hline
\end{tabular}

Table 4. ANOVA results for response R2 (TF).

\begin{tabular}{lcccccc}
\hline Source & Sum of squares & Df & Mean square & F value & p-value & Significance \\
\hline Model & 0.030 & 2 & 0.015 & 387.59 & $<0.0001$ & Significant \\
A-\% of ACN & 0.030 & 1 & 0.030 & 765.37 & $<0.0001$ & \\
B-Flow Rate & $3.840 \mathrm{E}-004$ & 1 & $3.840 \mathrm{E}-004$ & 9.81 & 0.0203 & \\
Residual & $2.349 \mathrm{E}-004$ & 6 & $3.915 \mathrm{E}-005$ & & & \\
Cor Total & 0.031 & 8 & & & & \\
\hline
\end{tabular}

Table 5. ANOVA results for response R3 (TP).

\begin{tabular}{|c|c|c|c|c|c|c|}
\hline Source & Sum of squares & Df & Mean square & F value & p-value & Significance \\
\hline Model & $2.281 \mathrm{E}+005$ & 2 & $1.141 \mathrm{E}+005$ & 9.26 & 0.0147 & Significant \\
\hline $\mathrm{A}-\%$ of $\mathrm{ACN}$ & $1.568 \mathrm{E}+005$ & 1 & $1.568 \mathrm{E}+005$ & 12.73 & 0.0118 & \\
\hline B-Flow Rate & 71286.00 & 1 & 71286.00 & 5.79 & 0.0429 & \\
\hline Residual & 73907.33 & 6 & 12317.89 & & & \\
\hline Cor Total & $3.020 \mathrm{E}+005$ & 8 & & & & \\
\hline
\end{tabular}

Table 6. Summary statistics for response R1, R2 and R3.

\begin{tabular}{lccc}
\hline Response & R1(RT) & R2(TF) & R3(TP) \\
\hline Std. Dev. & 0.24 & $6.257 \mathrm{E}-003$ & $6.257 \mathrm{E}-003$ \\
Mean & 3.37 & 1.37 & 1.37 \\
C.V. \% & 7.26 & 0.46 & 0.46 \\
PRESS & 0.69 & $5.832 \mathrm{E}-004$ & $5.832 \mathrm{E}-004$ \\
R-Squared & 0.8863 & 0.9923 & 0.7553 \\
Adjusted R-Squared & 0.8485 & 0.9898 & 0.6737 \\
Predicted R-Squared & 0.7823 & 0.9809 & 0.4748 \\
Adequate Precision & 13.433 & 43.554 & 8.448 \\
\hline
\end{tabular}

Table 7. The optimized method according to design of experiment.

\begin{tabular}{lcccccc}
\hline Method & \%ACN & Flow Rate $(\mathrm{ml} / \mathrm{min})$ & RT $(\mathrm{min})$ & TF & TP & Desirability \\
\hline Predicted level & 0.643 & 0.854 & 2.790 & 1.315 & 5291.514 & 1.000 \\
Actual values & 33.25 & 0.985 & & & & \\
Experimental & 33.0 & 1.0 & 2.754 & 1.326 & 5302.261 & \\
Deviation (\%) & & & 0.912 & 0.591 & 0.143 & \\
\hline
\end{tabular}



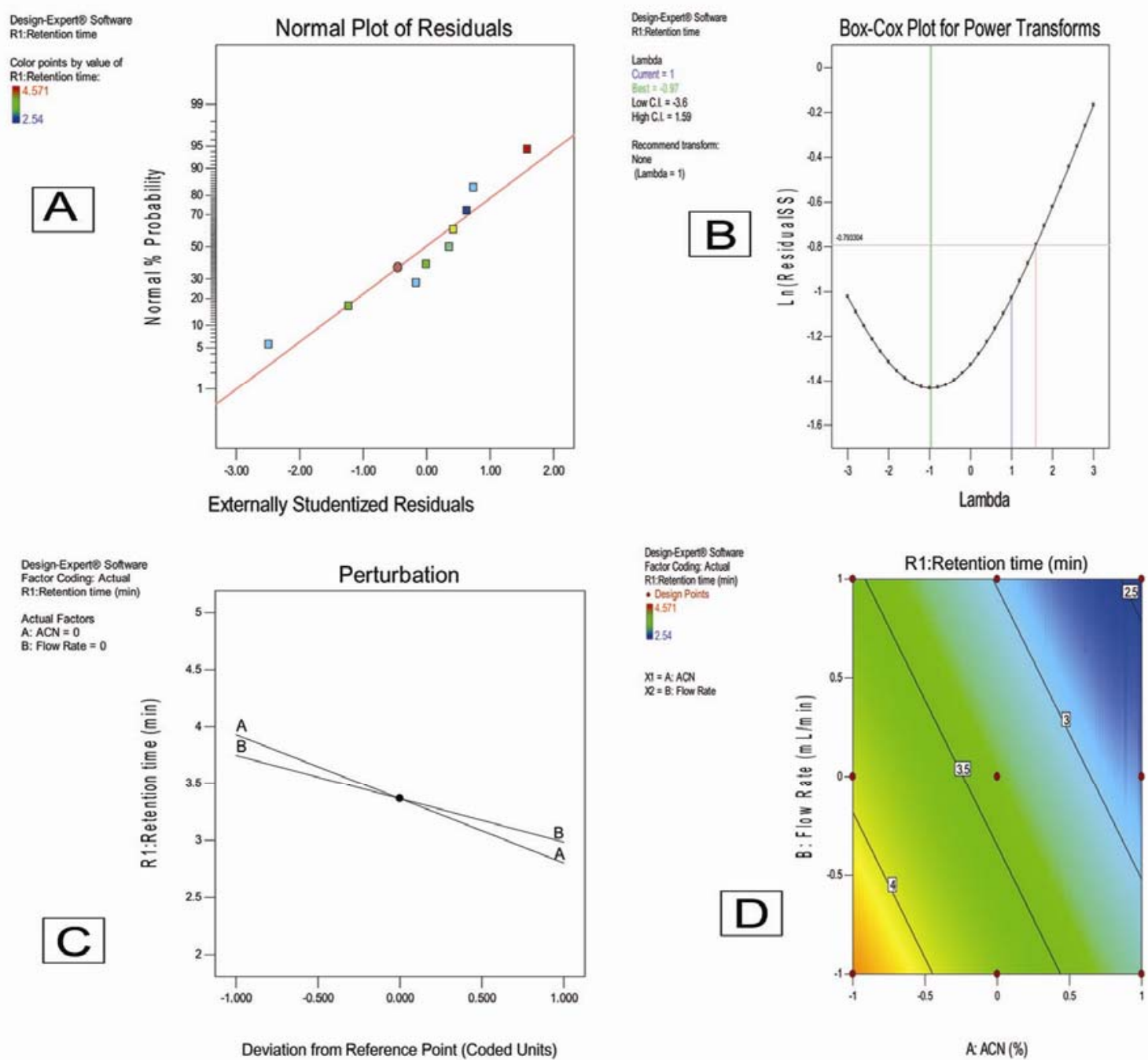

Deviation from Reference Point (Coded Units)

$\operatorname{A} \cdot \operatorname{ACN}(\%)$

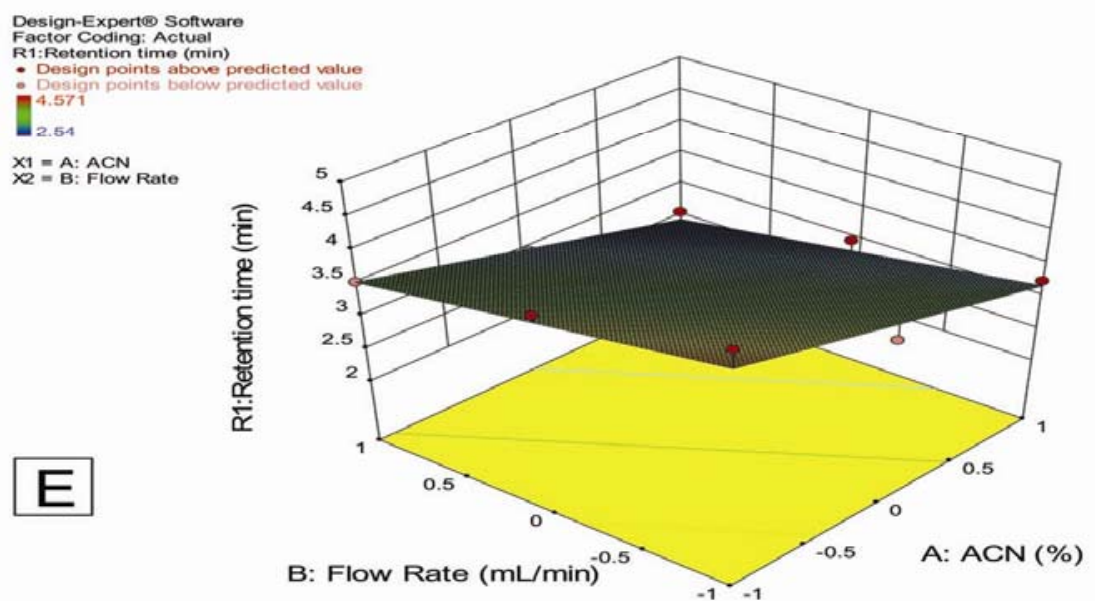

Figure 2. (A)-Normal plot of residual, (B)-Box-Cox plot for power transform, (C)- Perturbation, (D)-Counter Plot, (E)-3D response surfaces effect on R1. 

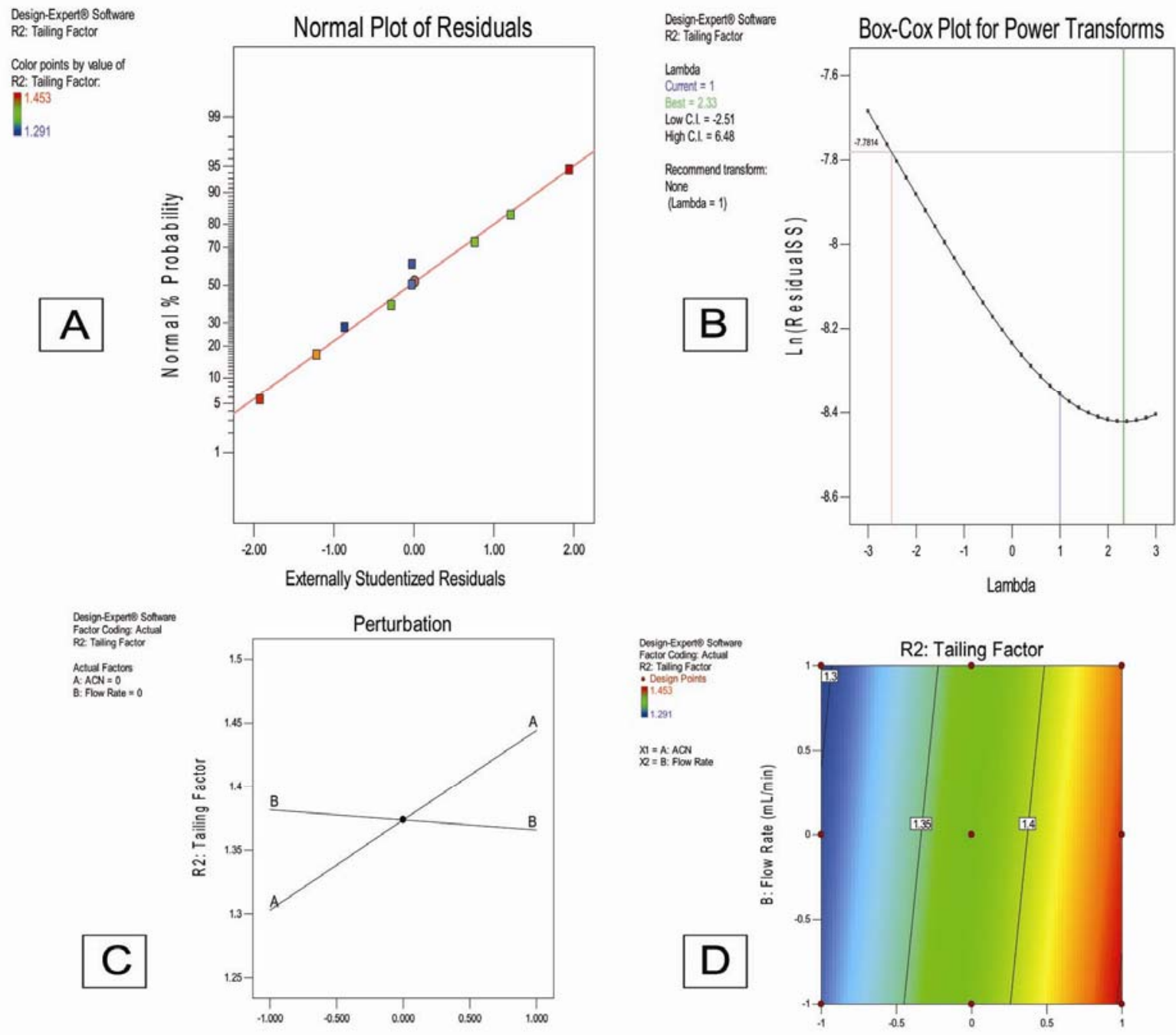

Deviation from Reference Point (Coded Units)

$A \cdot A C N(\%)$

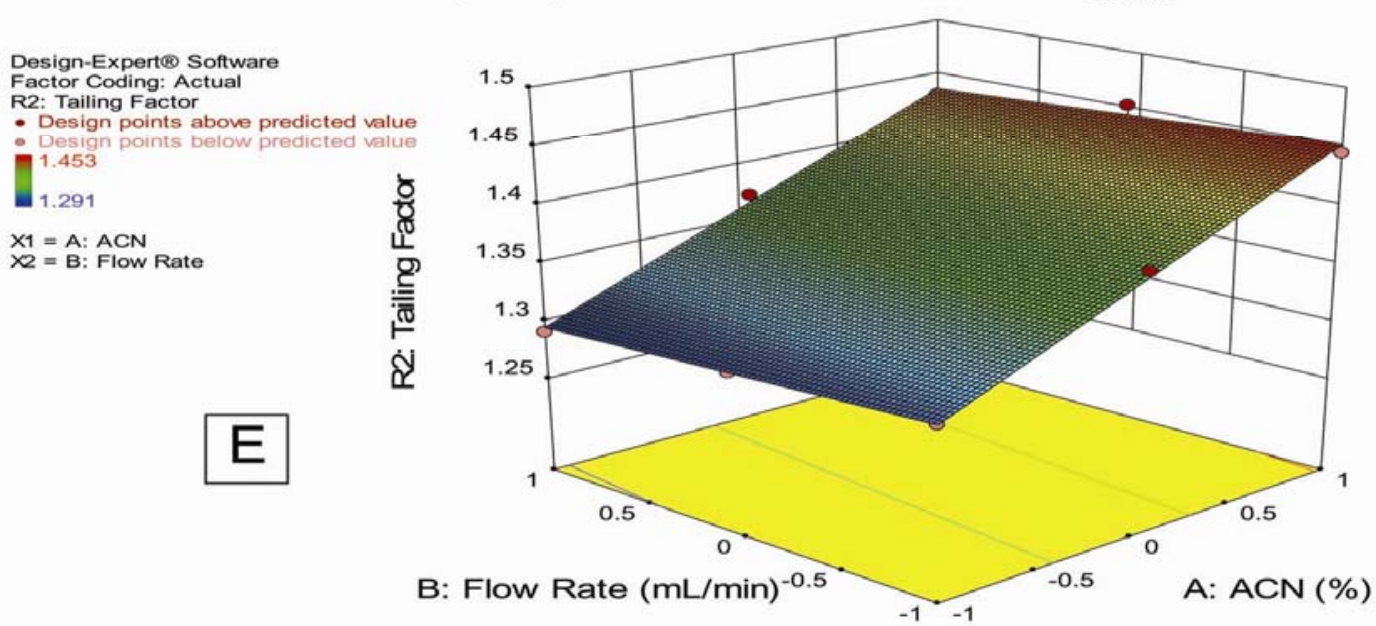

Figure 3. (A)-Normal plot of residual, (B)-Box-Cox plot for power transform, (C)- Perturbation, (D)-Counter Plot, (E)-3D response surfaces effect on R2. 

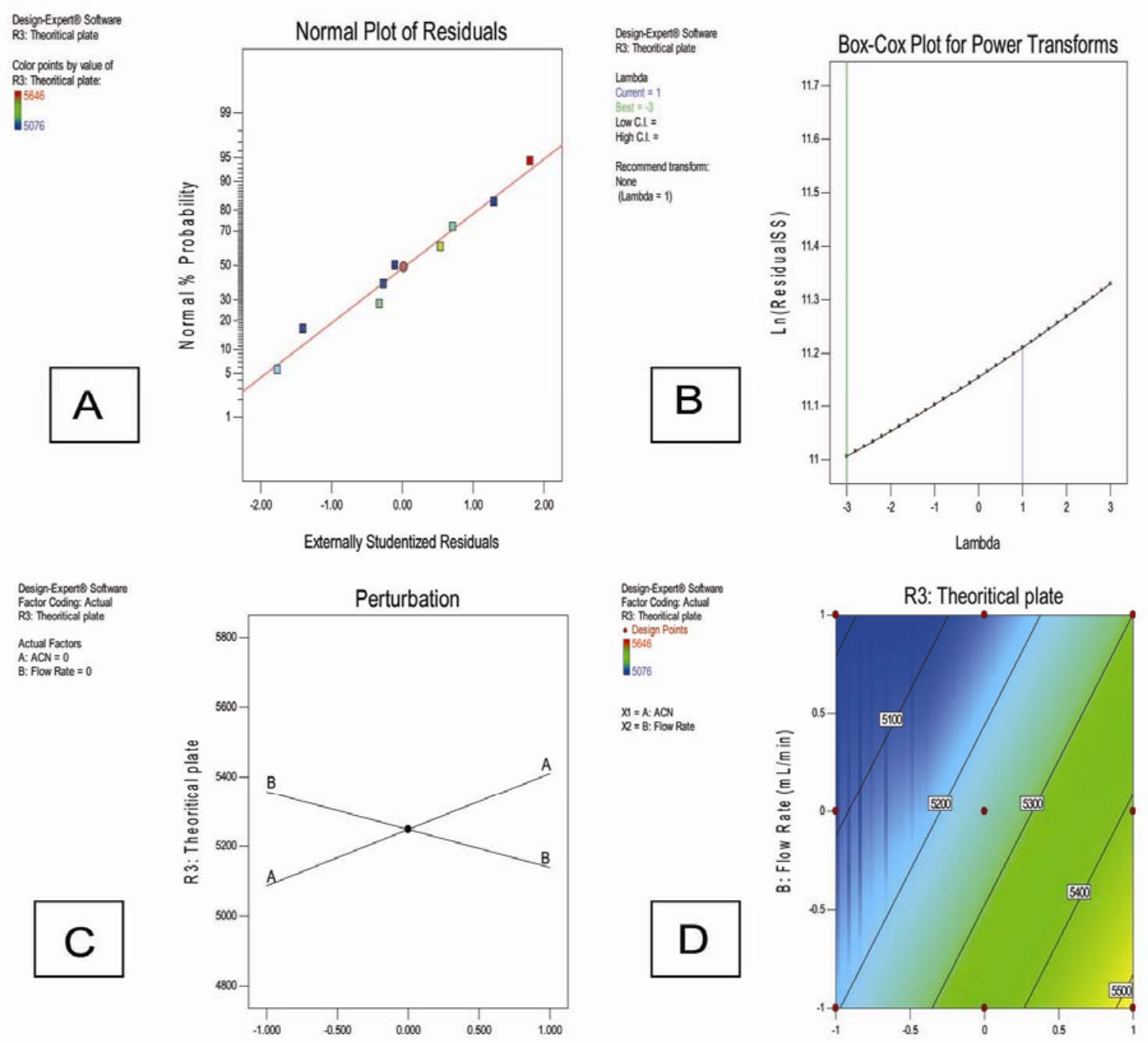

Deviation from Reference Point (Coded Units)

$A: A C N(\%)$

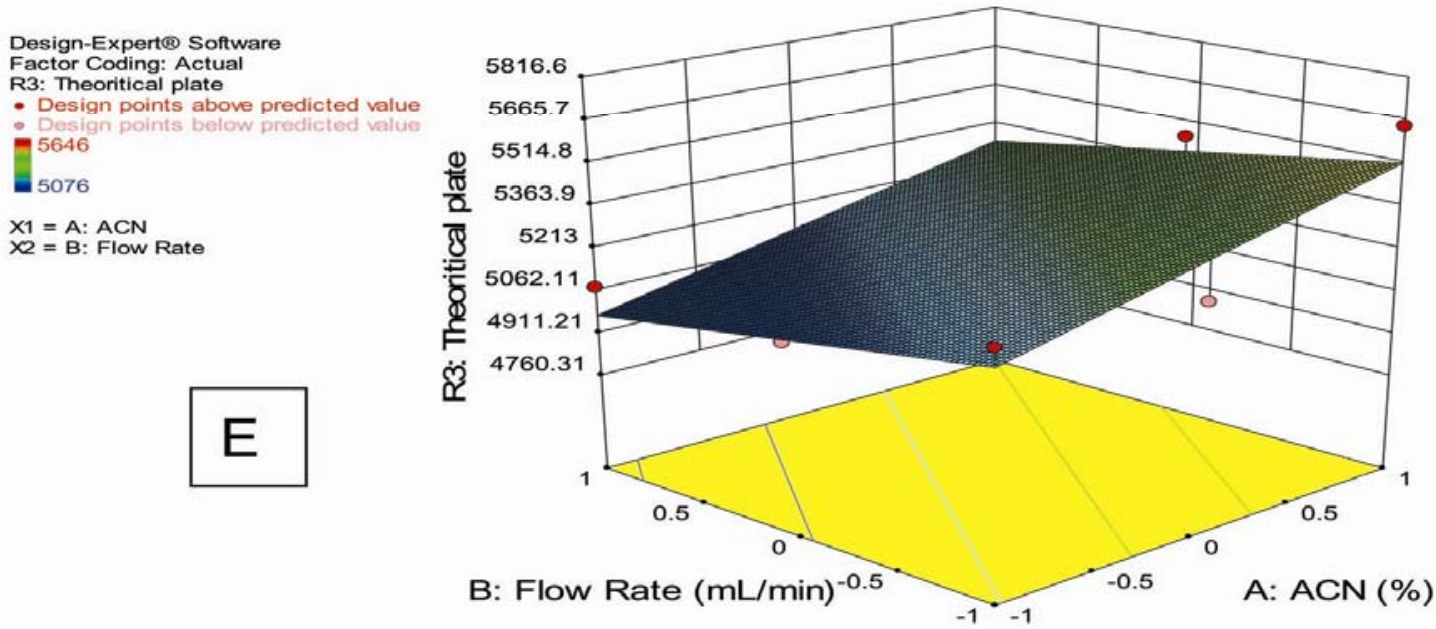

Figure 4. (A)-Normal plot of residual, (B)-Box-Cox plot for power transform, (C) - Perturbation, (D)-Counter Plot, (E)-3D response surfaces effect on R3. 
The sum of total 9 runs was obtained for the fixed variables in order to test the predictive validity of the model. Each combination of mobile phase composition and flow rate suggested by BBD were finally run on the system and observed for the responses such as retention time, tailing factor and theoretical plate count as represented in table 2 .

All experiments were performed in randomized order to minimize the effects of uncontrolled factors that may introduce a bias on the response. Among the various models, the quadratic model was suggested by the design with the maximum least square regression coefficients for all three responses R1, R2 and R3 as compared to other models.

The model was examined using Lack of Fit test, which indicated insignificant lack of fit value corresponding with higher $\mathrm{p}$-value as compared to the model F-value. Additionally, normal plot of residual indicated all the data were concentrated along the model fit line and there was no observable outlier in the data (Figure 2, 3, 4-A). Furthermore, the model was validated by the application of Analysis of Variance (ANOVA) which showed that the model was significant. The quadratic equation of all model responses $\mathrm{R} 1, \mathrm{R} 2$ and $\mathrm{R} 3$ are as follows:

R1 (Retention time) $=+3.37-0.57 \mathrm{~A}-0.38 \mathrm{~B}$

$\mathrm{R} 2$ (Tailing factor) $=+1.37+0.071 \mathrm{~A}-(8.00 \mathrm{E}-003) \mathrm{B}$

$\mathrm{R} 3$ (Theoretical plate) $=+5248.0+161.66667 \mathrm{~A}$ 109.0B

The results of ANOVA for responses R1, R2 and R3 showed that the model F-value of 23.39, 387.59 and 9.26 respectively implies the models are significant. The $\mathrm{p}$-values for the model terms showed that both the variables $\mathrm{A}$ and $\mathrm{B}$ are significant $(p<0.05)$ (Table 3, 4, 5) in all cases.

From the table 6 , the predicted R-squared for all responses R1 (0.7823), R2 (0.9809) and R3(0.4748) are in reasonable agreement with the adjusted Rsquared values of $0.8485,0.9898$ and 0.6737 , respectively i.e. the difference was less than 0.2 in each case. The signal to noise ratio was measured by the adequate precision. The ratio of $13.433,43.554$ and 0.4748 indicate an adequate signal (ratio $>4.0$ ). These models can be used to navigate the design space.

According to the 3D response surfaces and quadratic model equation it is observed that variables $\mathrm{A}$ and $\mathrm{B}$ both have negative effect on RT (Figure 2) and the variable $\mathrm{A}$ has positive effect and $\mathrm{B}$ has negative effect on both TF (Figure 3) and TP (Figure 4), hence it shows that the relationship between factors and response is not always linear, when one or more than one factor is altered simultaneously then a factor can result in different grade of responses. The statistical results for RT, TF and TP indicated

Table 8. Accuracy of vildagliptin.

\begin{tabular}{cc}
\hline Spike level (\%) & $\%$ Recovered $\pm \%$ RSD \\
\hline 80 & $99.54 \pm 0.02$ \\
\hline 90 & $100.20 \pm 0.04$ \\
\hline 100 & $99.88 \pm 0.13$ \\
\hline 110 & $98.25 \pm 0.06$ \\
\hline 120 & $101.50 \pm 0.03$ \\
\hline
\end{tabular}

Table 9. Summary of inter-day and intra-day precision for vildagliptin.

\begin{tabular}{|c|c|c|c|c|c|c|c|}
\hline \multirow{4}{*}{ Inter-day } & Time (hr) & 0 & 1 & 2 & 4 & 8 & 12 \\
\hline & Assay (\%) & 98.56 & 98.20 & 99.58 & 98.94 & 100.3 & 101.2 \\
\hline & Mean \pm SD & & & $99.63 \pm 0.971$ & & & \\
\hline & $\%$ RSD & & & 0.975 & & & \\
\hline \multirow{4}{*}{ Intra-day } & Day & 1 & 2 & 3 & 4 & 5 & 6 \\
\hline & Assay (\%) & 100.1 & 99.40 & 99.21 & 99.15 & 98.88 & 98.75 \\
\hline & Mean \pm SD & & & $99.25 \pm 0.478$ & & & \\
\hline & $\%$ RSD & & & 0.481 & & & \\
\hline
\end{tabular}




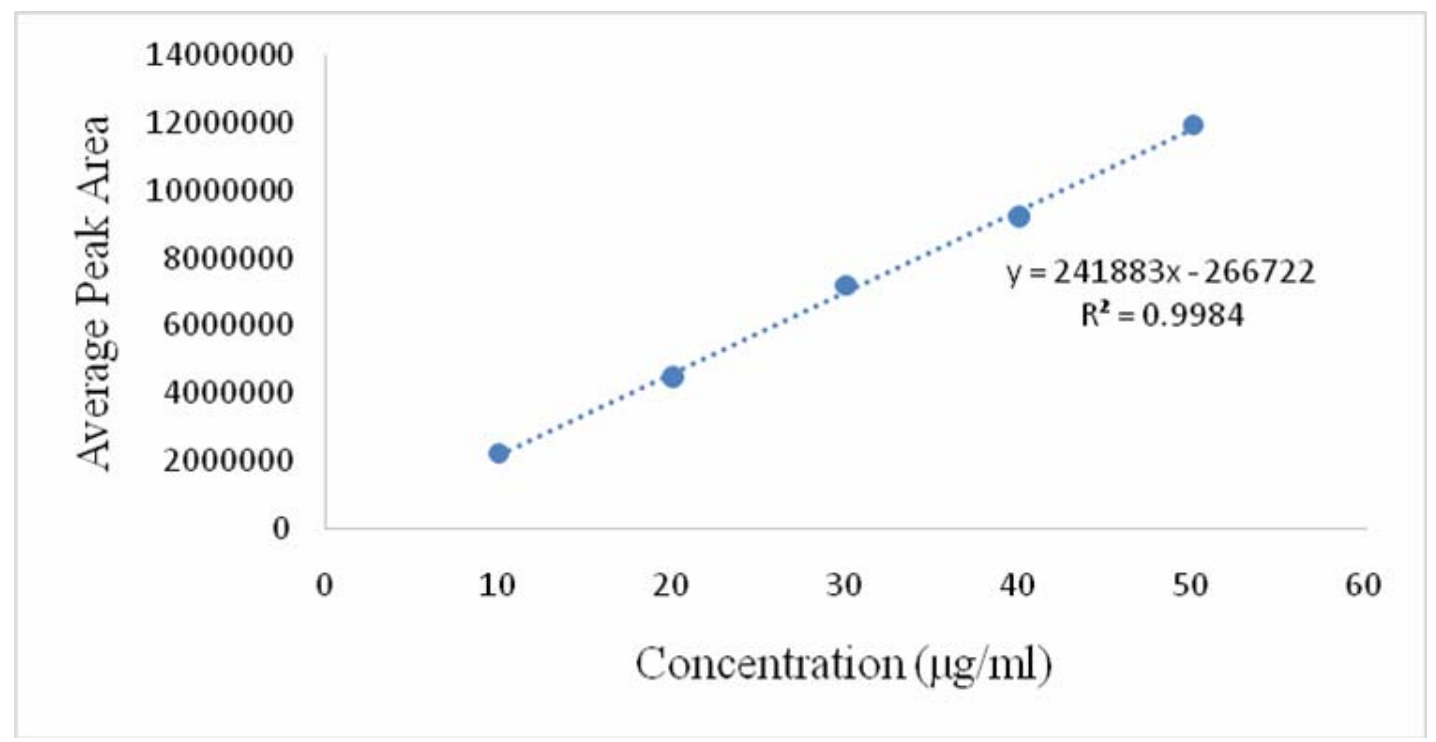

Figure 5. Linearity curve of vildagliptin.
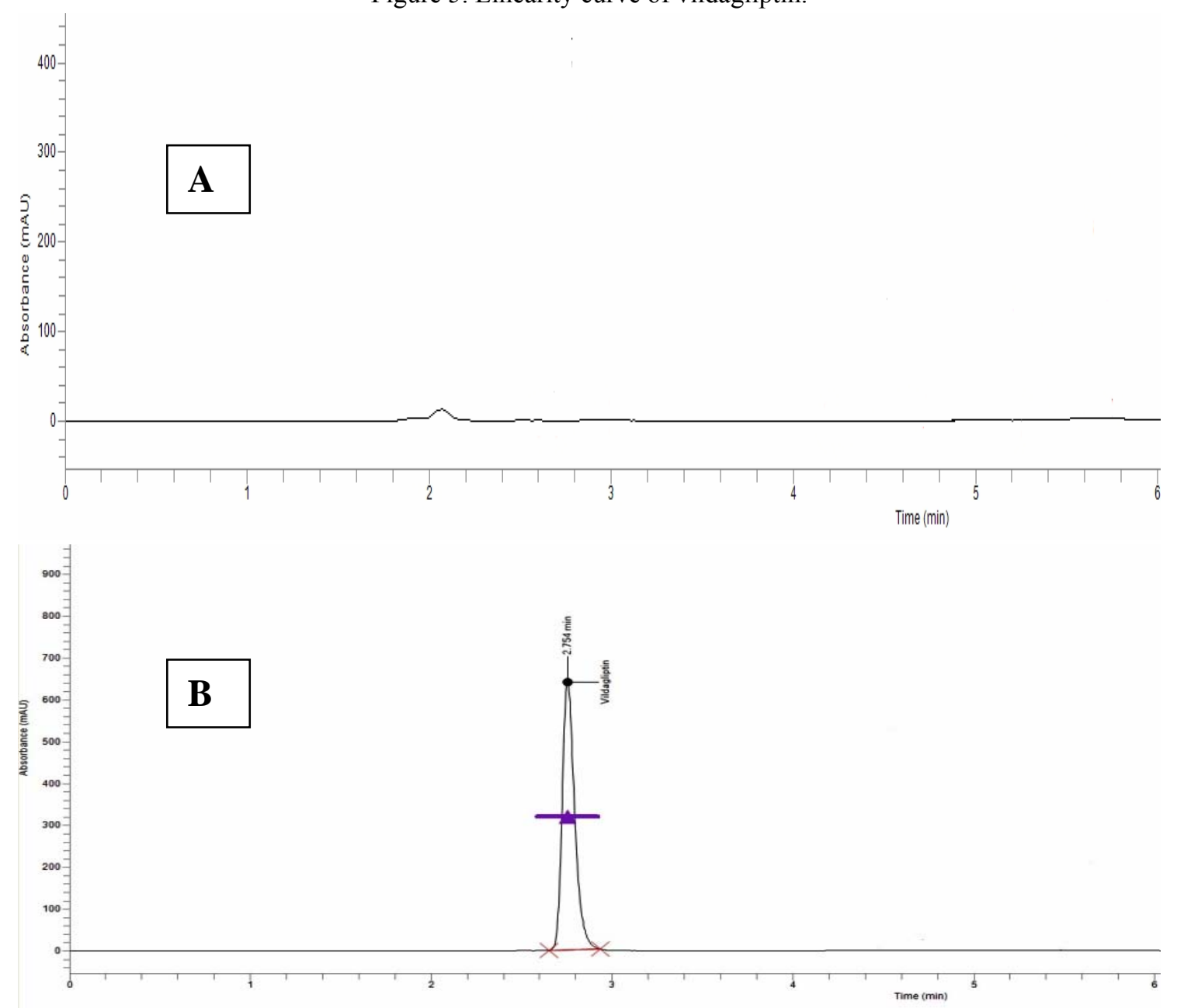


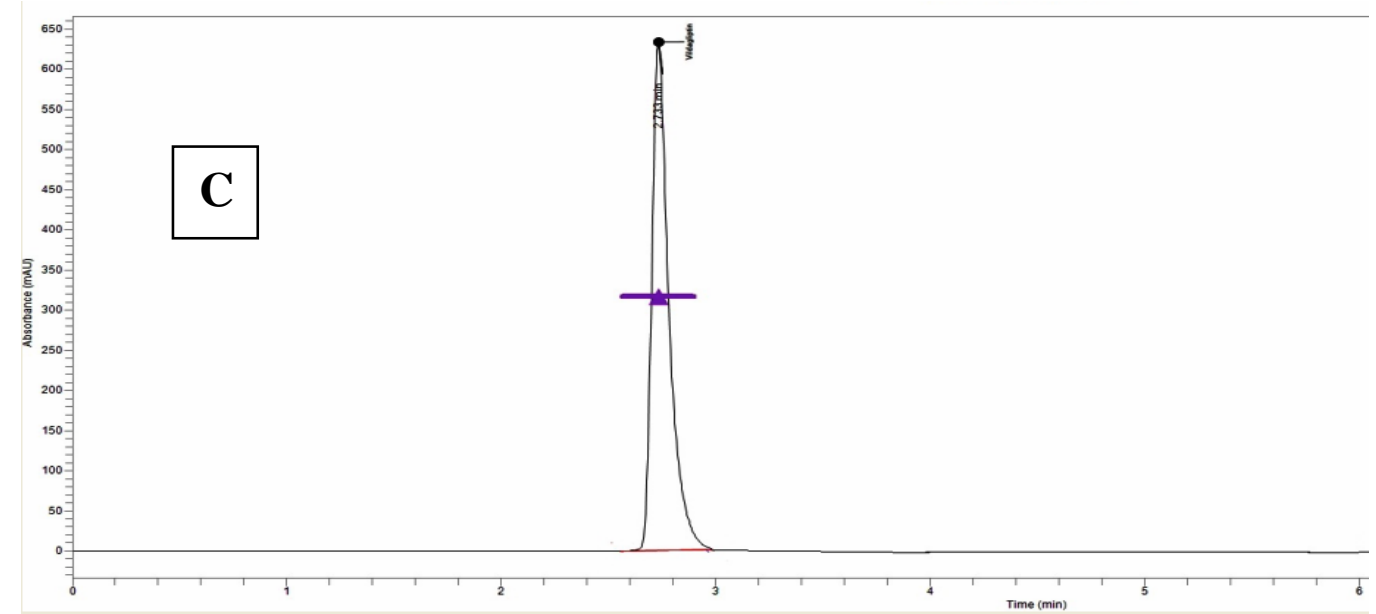

Figure 6. Chromatogram of (A)-Blank, (B)-Standard and (C)-Sample.

that the analytical method was robust since variations in the experimental conditions did not affect on the quantitative analysis of vildagliptin. The experimental results of the predicted method were found to be analogous with the suggested responses and all the results fall within the level of acceptance as shown in table 7 (NMT 2.0\%).

\section{Validation of the method}

A good linear relationship $\left(\mathrm{R}^{2}=0.9984\right)$ was observed between the concentrations of vildagliptin and the respective peak areas. The regression curve was constructed by linear regression and its mathematical expression was $\mathrm{Y}=241883 \mathrm{X}-266722$, where $\mathrm{Y}$ is the peak area and $\mathrm{X}$ is the concentration of vildagliptin (Figure 5). The LOD and LOQ values for the proposed method were found to be $0.01 \mu \mathrm{g} / \mathrm{ml}$ and $0.05 \mu \mathrm{g} / \mathrm{ml}$, respectively. The method showed that the \% RSD of recovery study was not more than $2 \%$. (Table 8 ). The method was also precise and the $\%$ RSD for repeatability and intermediate precision were within the limit (NMT 2\%) as shown in table 9. The UHPLC chromatograms recorded for the blank, standard and sample separately revealed that vildagliptin is clearly separated from the response of any interfering peak (Figure 6).

\section{CONCLUSION}

The developed RP-UHPLC assay method for vildagliptin by $\mathrm{QbD}$ approach was found to be linear, precise, reproducible, accurate and specific. The retention time and very low detection limit of this method indicated its high sensitivity, simplicity and selectivity. The method seems to be suitable for the quality control in the pharmaceutical industry and also for quantitation of drug substances in biological fluid during in vivo studies.

\section{ACKNOWLEDGEMENT}

This research work has been supported by Higher Education Quality Enhancement Project (HEQEP), AIF, Round-III, Window-2, CP-3245, Award No. 26, University Grants Commission (UGC), Bangladesh.

\section{REFERENCES}

1. Mikhail, N. 2008. Incretin mimetics and dipeptidyl peptidase 4 inhibitors in clinical trials for the treatment of type 2 diabetes. Expert Opin. Invest. Drugs 17, 845-853.

2. Thornberry, N. A. and Gallwitz, B. 2009. Mechanism of action of inhibitors of dipeptidyl-peptidase-4 (DPP-4). Best Pract. Res., Clin. Endocrinol. Metab. 23, 479-486.

3. Ahrén, B. O., Landin-Olsson, M., Jansson, P. A., Svensson, M., Holmes, D. and Schweizer, A. 2004. Inhibition of dipeptidyl peptidase-4 reduces glycemia, sustains insulin levels, and reduces glucagon levels in type 2 diabetes. $J$. Clin. Endocrinol. Metab. 89, 2078-2084. 
4. Mathieu, C. 2009. The scientific evidence: vildagliptin and the benefits of islet enhancement. Diabetes, Obes. Metab. 11, 9-17.

5. Croxtall, J.D. and Keam, S.J. 2008. Vildagliptin: a review of its use in the management of type 2 diabetes mellitus. Drugs 68, 2387-2409.

6. Booton, R. and Gilardi, J. 2012 Novartis unveils further impressive efficacy data for the investigational oral diabetes compound Galvus ${ }^{\circledR}$ showing significant blood sugar reductions. http://www.fiercepharma.com/pharma/novartisdata-at-ada-demonstrate-galvus $\% \mathrm{C} 2 \% \mathrm{AE}$-efficacy-andsafety-combination-insulin, Accessed date: 10 March 2017.

7. Wang, X., Zhang, D., Xu, W., Liu, H. and Wang, W. 2010. Pharmacokinetics of lipoyl vildagliptin, a novel dipeptidyl peptidase IV inhibitor after oral administration in rats. Xenobiotica 40, 707-712.

8. Edgerton, D.S., Johnson, K.M., Neal, D.W., Scott, M., Hobbs, C.H., Zhang, X., Duttaroy, A. and Cherrington, A.D. 2009. Inhibition of dipeptidyl peptidase-4 by vildagliptin during glucagon-like Peptide 1 infusion increases liver glucose uptake in the conscious dog. Diabetes 58, 243-249.

9. He, Y.L., Yamaguchi, M., Ito, H., Terao, S. and Sekiguchi, K. 2010. Pharmacokinetics and pharmacodynamics of vildagliptin in Japanese patients with type 2 diabetes. Int. $J$. Clin. Pharmacol. Ther. 48, 582-595.

10. Pharne, A.B., Santhakumari, B., Ghemud, A.S., Jain, H.K. and Kulkarni, M.J. 2012. Bioanalytical method development and validation of vildagliptin a novel dipeptidyl peptidase IV inhibitor by RP-HPLC method. Int. J. Pharm. Pharm. Sci. 4,119-123.
11. Ramachandra, P., Vasudevan, M. and Chandan, R.S. 2014. Development and validation of RP-HPLC method for the estimation of vildagliptin in pharmaceutical dosage forms. World J. Pharm. Pharm. Sci. 3, 2125-2132.

12. Varma, D., Lakshmana, R. A. and Dinda, S. C. 2013. Simultaneous determination of Metformin and Vildagliptin in solid dosage form by stability indicating RP-HPLC method. Int. Res. J. Pharm. 4, 122-128.

13. Chaphekar, M.M. and Hamrapurkar, P.D. 2016. Development and validation of RP-HPLC assay method for vildagliptin using Qbd approach and its application to forced degradation studies. Int. J. Pharm. Sci. Drug Res. 8, 157-165.

14. Waghulde, M. and Naik, J. 2016. Development and validation of analytical method for vildagliptin encapsulated

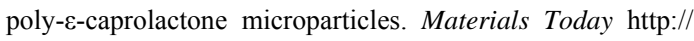
www.pmme.co.in/papers/EMT-221.pdf, Accessed date: 05 March 2017.

15. Naveed, S., Rehman, H., Qamar, F. and Zainab, S. 2014. Method development and validation of Vildagliptin using UV spectrophotometer. Int. J. Pharma Sci. Res. 5, 714-717.

16. Ferreira, S.C., Bruns, R.E., Ferreira, H.S., Matos, G.D., David, J.M., Brandao, G.C., da Silva, E.P., Portugal, L.A., Dos Reis, P.S., Souza, A.S. and Dos Santos, W.N. 2007. Box-Behnken design: an alternative for the optimization of analytical methods. Anal. Chim. Acta 10, 179-86.

17. International Conference on Harmonization 2005. Validation of Analytical Procedures: Text and Methodology, Q2 (R1). IFPMA, Geneva, Switzerland. 